\title{
Planning the Decision Making Process: A Multiple Case Study
}

\author{
Willy Hoppe de Sousa ${ }^{1}$, Maria Cecilia Galante Porto ${ }^{2}$, Maria Isabel Palmeiro Marcantonio ${ }^{2}$, Pedro Issao \\ Takenouchi ${ }^{2} \&$ Abraham Sin Oih $\mathrm{Yu}^{2}$ \\ ${ }^{1}$ Instituto de Pesquisas Energéticas e Nucleares, São Paulo, Brazil \\ ${ }^{2}$ Faculdade de Economia, Administração e Contabilidade, Universidade de São Paulo, Brazil \\ Correspondence: Willy Hoppe de Sousa, Av. Prof. Lineu Prestes, 2242, Instituto de Pesquisas Energéticas e \\ Nucleares, Cidade Universitária, São Paulo 05508-900, Brazil. E-mail: whsousa@ipen.br
}

Received: November 23, 2014

Accepted: March 31, 2015

Online Published: April 29, 2015

doi:10.5539/emr.v4n1p82

URL: http://dx.doi.org/10.5539/emr.v4n1p82

\begin{abstract}
The decision-making process involves making decisions about the decision process itself. Understanding better about "how to decide" decision makers can improve the quality of their decisions and using less time and resources. A multiple case study was developed to identify factors that may lead a decision-making process to be planned or unplanned. In the three cases studied we observed the planning of the decision-making process, however, with distinct degrees of effort and the time frame of the problem's occurrence and the decision-making. We identified five main factors that influence the planning of the decision-making process: i) the nature of the problem-whether the problem is new or recurrent to the firm, ii) awareness regarding the problem, the objectives and alternatives, iii) decision maker's experience, iv) organizational culture regarding risk taking in decision making, v) decision maker's autonomy level and holistic view of the firm and the conjuncture embedded. By studying the decision planning process of these three cases we believe we could draw attention to a perspective of the decision process seldom studied and open the possibility of new studies involving the decisions about the decision process - the meta-decisions.
\end{abstract}

Keywords: decision planning, meta-decisions, decision-making process

\section{Introduction}

One of the biggest challenges to the managers of an organization is decision-making. The continuing development of this skill is vital, because it is this skill of making decision properly that make difference in the results of the company (Shimizu, 2010). In order to accomplish superior performance, it is required the simultaneous use of rationality, intuition and experience (Bazerman \& Moore, 2010; Shimizu, 2010; Simon, 1997).

The decision-making process involves basically the problem, objectives, alternatives, evaluation, and implementation of the decision (Shimizu, 2010). Understanding these components, as well as the characteristics of the decision maker, organizational culture, autonomy level and hierarchical level of decision maker, the decision time frame and level of corporate alignment are critical for the proper planning of decision-making (Clemen \& Reilly, 2001; Keeney, 2004; Shimizu, 2010).

When a decision maker is facing a problem that requires choosing the best among different solutions he needs to make decisions about how this problem will be solved, i.e., he needs to reflect and decide about "who is doing what and when" (Kickert \& van Gigch, 1979) during the decision making process in order to identify and decide the best solution. By planning some of these meta-decisions, it's expected that the decision makers can optimize the decision-making process, have more control over the process and, can, therefore, reach decisions with better quality with less time and resources invested.

This paper presents a study where we investigated what leads the manager plan or not plan the decision-making process.

In more specific terms, we wanted to:

- Empirically study the decision-making process by examining the occurrence or not the planning of decision-making process. 
- Identify possible decision planning efforts patterns subjacent to the decision-making process.

- Identify which factors can impact the planning in the decision-making process.

\section{Basic Concepts of Decision Making}

This block of the article aims to recall some very basic concepts regarding three decision making perspectives: the decision, decision making process and meta-decision.

\subsection{Decision}

Decisions, regardless of levels of complexity, are routine in organizations. Decision making can be defined as: the choice of an alternative to be implemented (Nutt, 1991). According to (Simon, 1997), the decision-making does not merely refer to the act of making decision, but to the whole decision-making process.

(Kladis \& Freitas, 1995), categorize the decisions by their context and organizational level. At the strategic level, the objective is to develop strategies in order to the organization accomplishes its purposes. At the tactical level, decisions are related to the administrative management and at operational level are only executors of the decisions predetermined at higher management level.

According to (Ansoff, 1988), strategic decision-making are decisions whose nature of the problem involves the allocation of resources into products or market opportunities, and also strategic decision-making does not have a repetitive character.

\subsection{The Decision Making Process}

The decision-making process can be defined as a set of actions and dynamic factors that begins with the identification of a stimulus that requires action and ends with a decision made (Mintzberg, Raisinghi, \& Theoret, 1976). According to the authors, making decisions requires the implementation of a decision-making process, even being formal or informal, structured or unstructured. (Simon, 1997) postulates that the decision-making process is composed of: (i) the intelligence activity: at this step it is done the analysis of a problem or situation; (ii) at the design step it is comprised the development and the analysis of the possible alternatives and (iii) the activity of making a decision, evaluating and choosing the most appropriate alternative.

There are variations to the steps of a decision-making process, but in a general way, it is possible to fit them in the model proposed by (Ansoff, 1988): (1) perception of the problem or opportunity, (2) formulation of alternatives, (3) evaluation of alternatives and (4) choosing one or more alternatives for implementation.

The process of decision-making includes the recognition of a problem or opportunity, the analysis of the definition of the problem, namely, the way the problem is formulated guides decisions, and therefore, the alternatives and outcomes. Withal, involves setting goals to be accomplished, and those goals, are the central element to the formulation of alternatives and decision-making.

According to Nutt (1991), at the generation of alternatives stage alternatives may be uncovered in four ways: (1) survey of ideas within the organization or brainstorming techniques, (2) benchmarking techniques, (3) market research, (4) design: customized search for alternatives.

At the evaluation stage of the alternatives, it is necessary to compare the alternatives, and analyze how those alternatives contribute to the achievement of the objectives. At the last stage, the choice of alternatives, the decision makers have to choose the most appropriate alternative(s) for achieving the objectives.

The implementation of the decision occurs after the decision-making, but not every decision is implemented. According to (Robbins, 2000) this fact occurs primarily by organizational constraints. The post-implementation stage of the decision is important because at this stage happens the process of organizational learning (Russo \& Schoemaker, 1993).

\subsection{Meta-Decision}

When studying the process of decision making, an important concept should be considered - the meta-decisions, i.e. the decision or decisions regarding how to decide. This term is first mentioned in literature in a classic paper on decision-making processes authored by Mintzberg, Raisinghani and Theoret in 1976 (Mintzberg et al., 1976). These problematic choices about the decision-making process can be found in the literature with a wider or stricter focus, depending on the approach adopted by the authors. For example, in the form of choosing models (Beach \& Mitchell, 1978); (Shrivastava \& Grant, 1986) or in the definition of contextual features, such as structure, incentive schemes among others (Blenko, Mankins, \& Rogers, 2010) or as the choice of decision styles (Vroom, 2000), (Wang, 2000) or decision strategies (Nutt, 2002; Payne, Bettman, \& Johnson, 1993). 
According to (Russo \& Schoemaker, 2002), meta-decision can be defined as a set of activities that are decided and implemented over a decision-making process. The process of meta-decision can be divided into four elements: (1) problem question's structuring, (2) data collection, (3) conclusions and (4) learning. It is important to the decision maker, consciously or unconsciously, to go through each step. Structuring the problem question is to better define what is to be decided, gathering necessary information in order to arrive at the conclusions, and ultimately, learning. Normally, it takes more time to collect information and provide conclusions then structuring the question problem.

Mintzberg et al. (1976) classify meta-decision into two phases: planning and change. The meta-decision's planning refers to the outline of the solution, the strategy development and the resources' estimation required during the development of the solution. The meta-decisions change are those in which planning becomes a specific action. In this type of decision, operating choices as selecting routines or deciding resources to be allocated are particularly emphasized. The process of deciding how to decide-named as meta-decision is managed by a decision maker who aims to obtain a satisfactory decision, controlling the flow and the content of the information, and even, an organizational political control of the decision-making process.

Sousa and Yu suggested that the planning process of a decision-making can be organized around three key activities: (1) diagnosis of meta-decision context and evaluation of meta-decision problem, (2) selection/planning of the meta-decision strategies and (3) meta-decision strategies implementation. The first two refers to activities before the decision is taken; the third one after. These authors develop some guidelines for the first two activities expecting that if a decision maker group follows them they can optimize the process of decision making and thus achieve higher-quality decisions with less time and less resources invested (Sousa \& Yu, 2014).

Frequently, the decision makers develop all the steps of decision-making process, but at the moment of the decision, some decision makers may use the intuition and the heuristics. At this moment, the brain processes all the information it holds, automatically and quickly, without being aware of any detail, not taking into account all available information. The use of intuition presents an advantage over decision-making with systematic methods, because it allows faster decision-making (Russo \& Schoemaker, 1993).

\section{Research Methodology}

The research methodology adopted a qualitative and exploratory perspective. Multiple cases were studied. The multiple case study is considered more cogent and robust than the single case study, by having greater capacity for analytical generalization (Yin, 2003). According to (Roesch, 1999) there are two significative perspectives on case study: (i) deeply study the phenomenon within its context and (ii) study of the phenomena from different angles of analysis.

Langley (1999) suggests seven strategies for studying decision processes - a combination of aspects of three of them were employed here: (1) narrative strategy, as a preliminar data analysis step; (2) temporal bracketing strategy, where data are decomposed into successive periods and, by thus, viabilizing analysis of feedbacks mechanisms or muldirectional causality and (3) grounded theory strategy, in order to propose new theories derived from data.

Data analysis is the central issue in multiple case studies, because the goal is to identify patterns and compare data from each case study. The use of tactics is an attempt to identify trends and patterns by analyzing the data in different ways. One of the tactics is to analyze the cases by selecting categories and identifying similarities and differences between cases (Eisenhardt, 1989). In this paper, the cases were compared in order to identify similarities and differences concerning the occurrence of the decision planning. Three cases were studied in this paper: i) Replanning of the firm's operations case (RPO), ii) Managers development case (MDE) and iii) New product development case (NPD). The primary data were obtained from interviews with managers of these three organizations, using a semi-structured interviews script with open questions, developed in the light of the literature review. The secondary data — data about the companies - were used to provide important clarifications and foundations and were also the basis for the interviews that were conducted, because they facilitate the formulation of the script and the interpretation of primary data (Malhotra, 2006).

The cases were selected considering the following criterias: (i) company size, (ii) ease of access to managers that were actively involved in the decisions, (iii) position held by managers in the organization: middle managers, and (iv) willingness to report on a strategic decision made in the past.

Regarding the interview process, the main challenge was to re-connect the managers to the period in which the decision problem was detected and reconstruct the events arising from it. Secondly, it was necessary to explore meta-decision, through the analysis of whether or not there was planning prior to making the decision, as well as 
the analysis of the factors that impacted the planning of the decision-making process.

In the RPO case, three face-to-face interviews were held in the first half of 2011. These interviews were recorded, transcribed and there was also a contact by e-mail. In the MDE case there were two face-to-face interviews in May and June 2011, plus telephone and e-mails contacts. The content of the interviews was recorded. In the case of NPD, there were two face-to-face interviews in May 2011, only the first interview was video recorded, and in addition to the interviews, contacts by email were made. Moreover, the content of the interviews was manually registered by the researcher.

\subsection{The Conceptual Model of the Research}

The conceptual model of the research aims to explain, either graphically or in narrative, the main aspects that will be the object of research (Miles \& Huberman, 1994). At the present study, the generic model of a meta-decision process of a decision-making process proposed by Sousa (2007) was taken as a theorical starting point to build the conceptual model of the present study. This generic model was proposed by combining the studies of Kickert and van Gigch (1979), the integrative framework for strategic decisions proposed by Rajagopalan, Rasheed and Datta (1993) and the results of analysis of the meta-decisions identified in seven strategic decisions taken in a governamental organization. In that study the entire decision process was analysed and as final results proposed that some logics may be behind the process metadecisions regarding the participants, the phase of the decision process, the structure of the analysis and the influence level employed along the decision process. At the present study we performed a simplification and adaptation of this generic model by focusing the analysis only on the planning meta-decision and by considering only few contextual decision process aspects from the decision maker and the organization chracteristics, as shown in Figure 1.

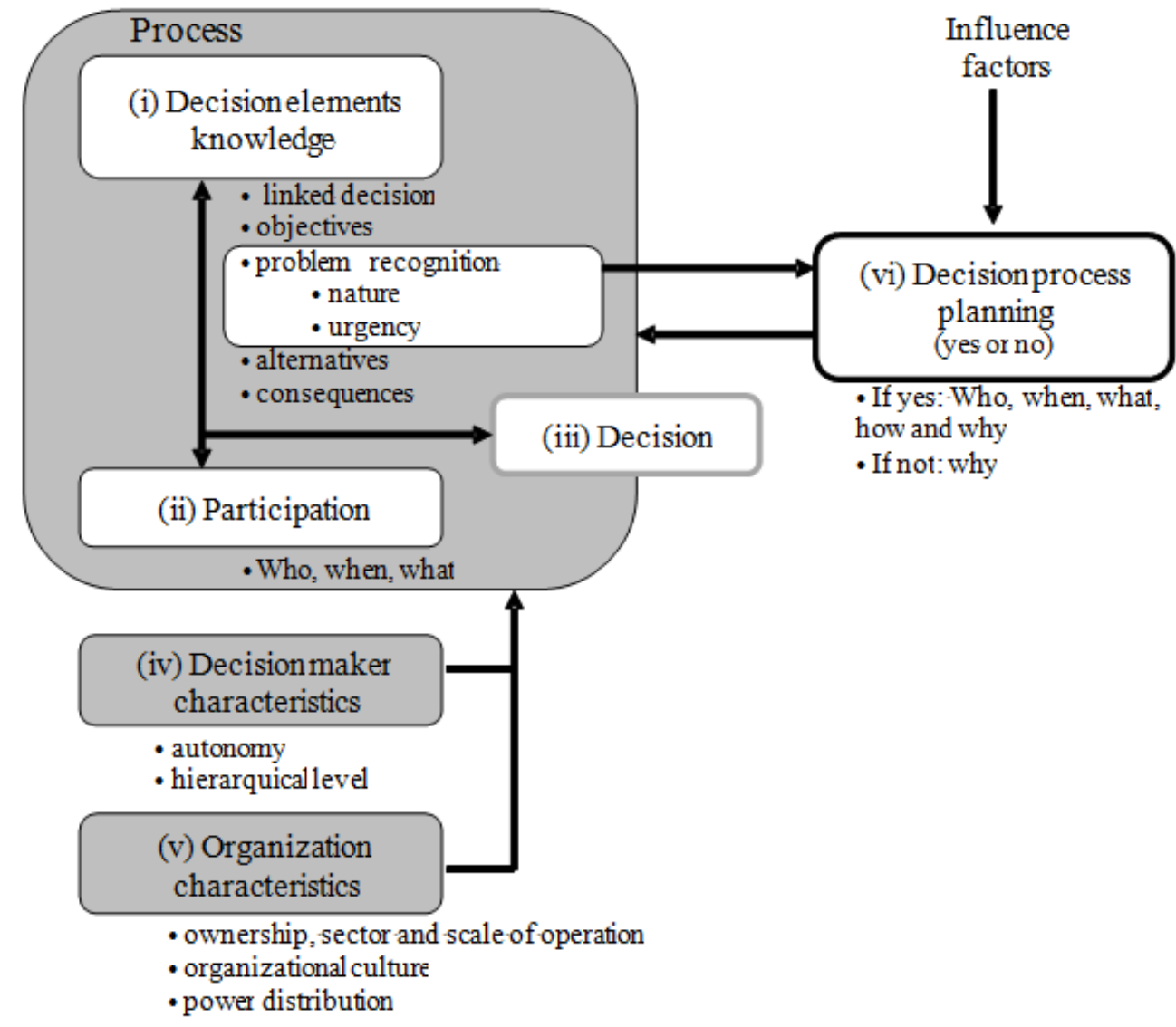

Figure 1. Conceptual model of the research

Source: Simplified and adapted by the authors from Sousa, (2007).

This conceptual model organizes and illustrates the relationships among groups and sub-groups of variables.

The process group is subdivided into three sub-groups of research variables: (i) the "knowledge about the 
elements of a decision", (ii) the "participation" and (iii) the "decision."

The sub-group (i) consists of the following variables: "linked decisions", "objectives", "problem recognition", "nature of the problem," "urgency of the problem", "alternatives", and "consequences".

The sub-group (ii) it is compounded by the variables "when" and "who" was involved in the decision, and the variable "what", represents the actions to be performed during the decision-making process. The sub-groups (i) and (ii) may influence one another along the decision-making process.

The sub-group (iii) represents the final outcome of the decision-making process and is represented by a single variable: the decision.

The decision-maker characteristics group (iv) consists of the following variables: The "autonomy" of the decision-maker in relation to decision-making and the "hierarchical level" occupied by the decision-maker in the organization.

The organization characteristics group (v) considers the following information about the organization: ownership, sector and scale of operation, organizational culture and power distribution.

The planning decision-making process group (vi) was characterized by only by to status "yes" or "no". It was categorized as "yes" in the event of a schedule in the form of a conscious sketch of the steps to be followed to make a decision. In that situation, we tried to investigate the variables "who planned", "when planned", "what planned", "how planned" and "why planned" at the moment of the recognition of the existence of a problem requiring a decision. In the case it was categorized as "no" we sought to investigate why there was no planning.

As shown in Figure 1, the conceptual model of the research assumes the existence of a bidirectional relationship between the "process" and the "planning decision making process" that can be explained as follows: depending on the problem a planning process of decision-making is activated or not. This plan, if enabled, will influence the development of decision making. In its lower part of the conceptual model of the research the influence of the groups "characteristics of the decision maker" and "characteristics of the organization in the decision-making process" are shown including the variables to be mapped cases to be investigated.

The model further assumes the possibility of factors that may be influencing the decision-making process planning group.

In order to operationalize this model, an interview protocol was developed (see Appendix A) to collect the data. Later on, considering the three strategies earlier mentioned the data of these interviews were analysed. Content analysis was employed to identify each element of conceptual model, "rebuilt" the case and identify the factors that could lead a decision maker to plan (or not) the decision-making process (Flick, 2004).

\subsection{Description of the Organizations}

The first organization (company A) presented in this paper is Brazilian which operates in the food industry and has several production units deployed. The decision case of this company will be referred to as "Replanning of the firm's operations" (RPO). The manager, who is the key figure in this decision, occupies a position of middle management and reports to the regional director. He is responsible for a small production plant (referred as unit $\mathrm{Y}$ ) in relation to the other units of the organization (a especially new one will be referred as unit X). The second company (company B) is a multinational, it operates in the retail sector and food service, and has stores throughout the country. The decision case of this company will be referred to as "Managers development" (MDE). The manager, who is the key figure in this decision, holds a management position reporting directly to two directors of training in Brazil and Latin America. The third organization (company C) is also a multinational, it operates in the financial sector and has service stores worldwide. The decision case of this company occurs in the United States of America, and will be referred to as "New Product Development" (NPD) and involved the launching of a new product (referred as product $Z$ ). The manager, who is the key figure in this decision, occupies a management position reporting directly to directors of the company in the United States of America.

\section{Decision Making Process}

\subsection{Replanning of the Firm's Operations Case (RPO-Company A)}

In 2008, after tracking data related to production planning, the manager found a downward trend in volumes produced at plant $\mathrm{Y}$ and reported this fact to his direct supervisor, the regional director. The fall in production was caused by a previous decision in which the company chose to migrate the production of many products from $\mathrm{Y}$ to $\mathrm{X}$ due to tax benefits enjoyed by plant $\mathrm{X}$. This decision had as consequences the gradual reduction of the volume of the production and the total revenue of plant $\mathrm{Y}$. The most serious consequence would be the risk of its closure. The problem to be faced by plant $\mathrm{Y}$ was defined by the manager as the vulnerability of this plant due to 
the oscillations of its production volumes.

In the following timeline, it is possible to visualize the decision $\left(D_{n-1}\right)$ which gave rise to the problem $\left(P_{r}\right)$, and the decision $\left(\mathrm{D}_{\mathrm{n}}\right)$ which was implemented in the attempt to solve the problem.

Company A: Replanning of the firm's operations

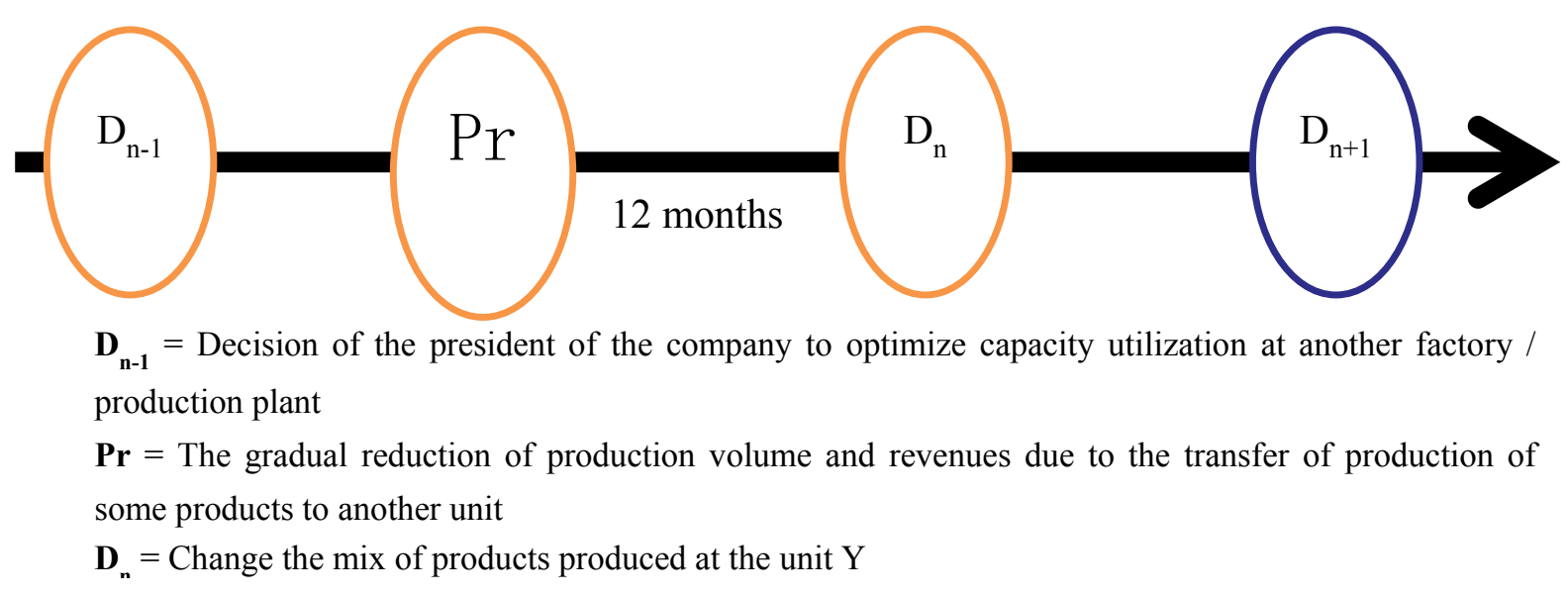

Figure 2. Timeline of the decision making process of the Company A

Source: Elaborated by the authors.

The decision-making process since the detection of the problem lasted 12 months. Four months after the identification of the main problem, the manager in combination with the department of marketing, costs, and research and development, proposed three alternatives for solving the organization problem: (i) the plant $\mathrm{Y}$ would start the poultry slaughtering, (ii) reduction of the number of shifts worked, as well as overtime and (iii) a change in product mix. The alternative of poultry slaughtering was discarded due to the U.S. crisis which reduced the consumption of poultry and, consequently, the volume exported by the company A. The second alternative, reducing the number of shifts was implemented temporarily, but with the production resumed later on, in plant $\mathrm{Y}$, the company returned to operate with two shifts. The third alternative - change the product mix - would be good to preserve the employment of all employees at the plant $Y$, since it could increase the profitability of the unit and would be an attempt to avoid the closure. This alternative would also have other consequences: there would be a reduction of the machine setup, cost reduction with internal transfer of byproducts and the maximization of financial return. The manager has drawn up a spreadsheet with the products should be evaluated as to the ingredients, costs, technologies for collecting and analyzing data. In the period in which the analysis of the information to define the most appropriate product mix were made, different areas of the company were involved, including the regional area of marketing, the cost area, the area of research and development, the engineering area and plant $\mathrm{X}$.

The way the matter was discussed in the company allowed the units $\mathrm{X}$ and $\mathrm{Y}$ to cooperate in defining what products should be produced in each location, taking into account criteria such as cost, logistics and technology. The units were in a state of coopetition, i.e., cooperating and competing simultaneously. This situation of coopetition was interesting for both plants, since for some products unit $\mathrm{X}$ had lower manufacturing cost and for others the costs were higher.

The definition, implementation and monitoring of the activities were included in meeting minutes.

The approval of the alternative generated and the implementation of the decision was a shared decision between the areas involved, since there was constant monitoring of the board of directors and the CEO. The decision for the change in the product mix of the units $\mathrm{Y}$ and $\mathrm{X}$ was actually made and implemented.

\subsection{Managers Development Case (MDE-Company B)}

In 2007, Company B in Brazil underwent a merger and acquisition (M\&A) by an international group. The feeling at the end of 2007 was uncertainty on the part of employees, especially senior managers due to the 
division of functions and changes in the organizational hierarchy. The directors who originally reported directly to the Brazilian CEO started to report to the vice-presidents of the areas that were in the headquarters abroad. The challenge for the CEO in Brazil was how to deliver the expected results with directors working alone in their duties. In addition, the new strategic plan for the year 2008 contained more aggressive goals.

The consequence of this acquisition was the onset of an unstable climate of organizational change and this would be a complicating fact to the implementation of the new strategies. The decision problem was characterized by the manager as possible demotivation and operational inefficiency of managers due to insecurity in relation to organizational changes.

In the timeline below it is possible to visualize the decision $\left(D_{n-1}\right)$ which gave rise to the problem and the decision implemented in the attempt to solve the problem $\left(D_{n}\right)$.

Company B: Management development program

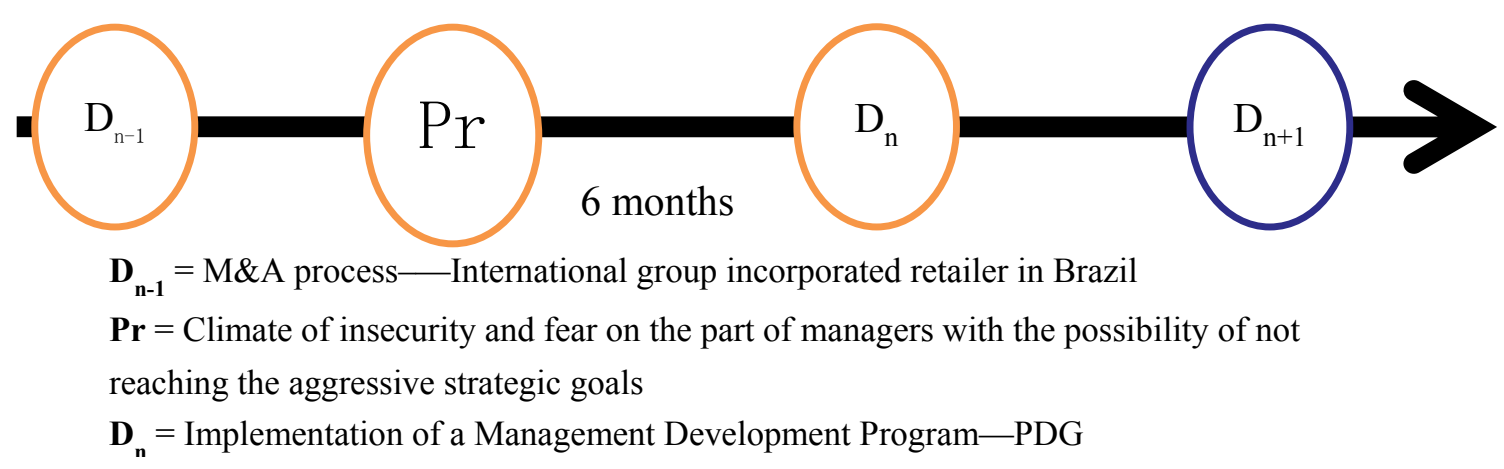

Figure 3. Timeline of the decision making process of the Company B

Source: Elaborated by the authors.

From detecting the problem until the actual decision was made the decision-making process lasted six months. Once the problem was detected, the manager masterminded the decision-making process mentally for the decision to be implemented. Firstly the manager thought of the execution of a Management Development Program involving the Directors. Through experience and expertise in the field of training, the manager believed that this program would create a sense of team among the Directors and CEO in Brazil. This cohesion would strengthen them and leave them emotionally and technically prepared to address organizational changes and deliver the results expected by the new management. According to the manager, he had the inspiration and the personal judgment of what would be a successful program. The next step would be to expose the problem and proposed solution in an organized manner to the two Directors of the company in Brazil. By convincing the Directors, the manager believed they would defend the idea with the CEO in Brazil so that the program could be implemented.

In a subsequent step, it was decided to seek external consultants to format and program the implementation. This occurred because the complexity of a such program to a higher hierarchical level was an unprecedented situation for the manager, and he did not hold the competence of the systemic view of the business development program at that time. Furthermore, due to his hierarchical limitation, not all information on the strategy of the business came to him and the program would be grounded in preparing officers for future scenarios. The consequence of this alternative would be a higher cost of the program because of its formatting and running by a consultancy, but the budget directed to the training area for the year 2008 would absorb this cost.

The manager did not involve other areas during the planning decision-making process basically for three reasons: first, because the demands of developing people is the responsibility only of the training area, and secondly due to organizational culture and thirdly, unavailability a team manager who could share ideas. If the manager had a team to share and discuss the project, it would give him greater security in the bid evaluations, but that wasn't the situation — so he had to go ahead without further internal preliminary discussions.

After the development and evaluation of proposals from consulting firms-something that consumed about 50\% of the time between the detection of the problem and the final decision - the manager gave the material for 
analysis and validation of the two Directors. The manager used as an argument with them the chance of getting closer to the CEO in Brazil and the possibility of forming a strategic alliance between the Directors and the CEO.

Only one of the Directors supported the alternative and took the program to the knowledge, validation and approval of the CEO. The argument used by the Director to sensitize the CEO was that the program would help directors understand and face the change process, increasing the Group's performance, delivering the expected results and creating a sense of regional team in Brazil. The decision to implement the Management Development Program was effectively taken by the CEO in Brazil.

\subsection{New Product Development Case (NPD_Company C)}

The strategic goal of generating revenue for the company $\mathrm{C}$ implied the need for creating, developing and launching constantly new products. In the case investigated here-the decision to release financial product $\mathrm{Z}$ - the manager saw an opportunity to develop and bring to market a new financial product that could contribute to the increase in revenue. In the timeline below the decisions which gave rise to this opportunity $\left(D_{n-3}, D_{n-2} e\right.$ $\left.D_{n-1}\right)$ are displayed, as well as the decision which was implemented $\left(D_{n}\right)$.

Company C: Development of a new product

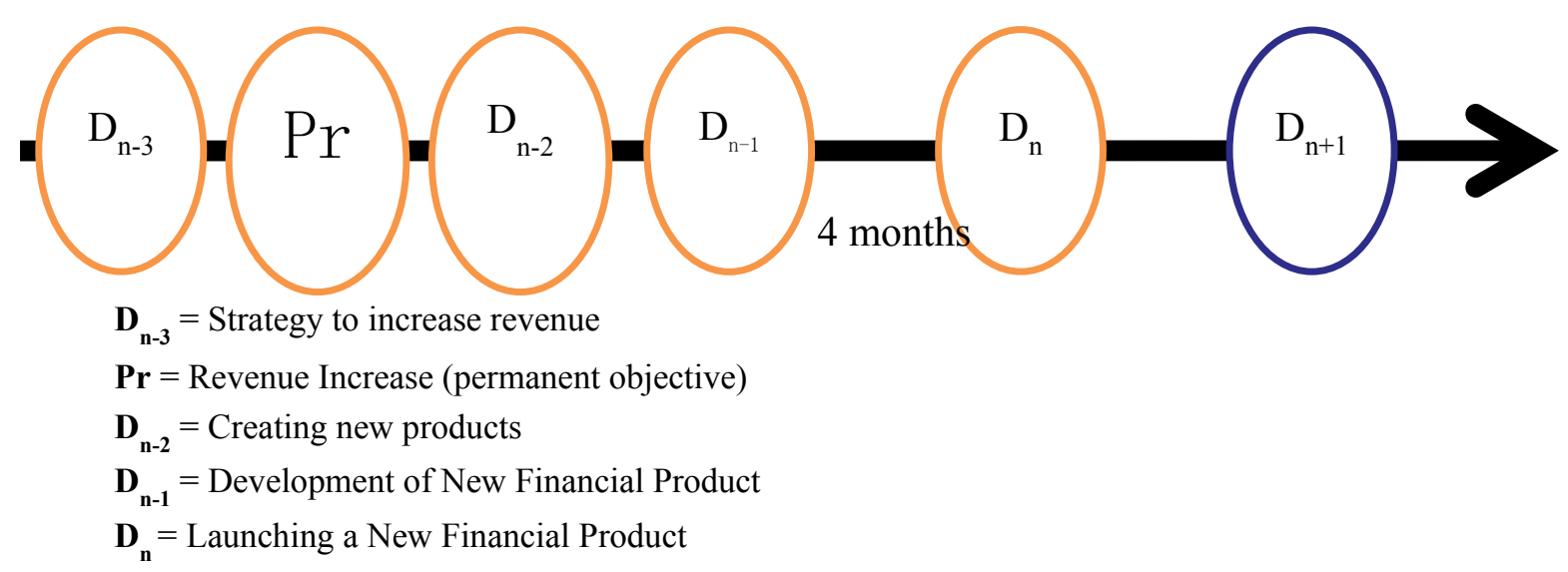

Figure 4. Timeline of the decision making process of the company $\mathrm{C}$

Source: Elaborated by the authors.

The strategy mentioned above creates a situation in which the objectives and the problem to be dealt are stable, $\mathrm{i}$. e., how to increase the revenue by constantly creating, developing and launching constantly new products, respectively. This condition generates situation for the decision making process where each decision to launch the product does not require specific planning for selecting a solution, since there is already a process formatted and pre-established program prepared by company $\mathrm{C}$ for this purpose. According to the manager, this structured process comes from experience and organizational learning processes, which turned into knowledge expressed over the decades of the company's existence.

This process covers from creation through development to the launch of a new product introduced by the company's headquarters to all branches worldwide.

After the creation process the best project is approved by the finance and marketing departments and sent to the development phase. From the development department, the project is sent to the specific business department that the product is going to belong, this project will be develop in conjunction with the departments of finance, marketing, operations, risk, compliance as well as the legal department. The process of developing and launching lasts 4 months.

In the case of the financial product $Z$, we investigated the developing and launching steps. After the analyses by the department of marketing and finance, the product $Z$ was considered the best project. In this development process there was a great interaction between the various departments in conjunction with the manager. It took the endorsement of each department on the development so that the project would follow for the next phase, where a meeting was held with the board of the company. At this stage, the development project was sent to the 
CEO who has the power to veto or sanction the release of product $Z$. Throughout the decision-making process the CEO participated indirectly, taking note of the status of each phase of the project and providing extra-protocol recommendations. The decision to launch the product $\mathrm{Z}$ was approved by the CEO.

\subsection{Analysis of the Cases}

The decision-making processes were planned or not?

In order to answer this question, let's recall the problems that demanded for a decision making process in each case. Analyzing the nature of decision problems of the RPO case, the problem in Company A can be classified as emergency situation - at least from the Company A's perspective, since the continuity of the plant $Y$ was at stake; in the MDE case the problem emerged from an organizational change resulting from new owners in Company B and in the NPD case a recurring problem associated with a goal of continuous search for improvement of organizational performance grounds the decision-making process in Company $\mathrm{C}$.

In the RPO case, after identifying the problem, when the manager took the initiative to involve the head and other areas to discuss the problem, there were no evidence that characterized some planning effort as the decision-making process should be developed. It seems that planning actions on the decision-making process were developed during the implementation of the decision-making process.

In the MDE case, we found that when the problem was recognized, the manager developed mentally a solution to the problem almost immediately after its recognition.

In the NPD case it was found that there was no need to develop any planning effort by the manager on how the process of decision making should be executed since in Company $\mathrm{C}$ a pre-set decision process to launch products already exists.

The way the alternatives were generated also provide additional information on the occurrence or not of the planning decision-making process.

In the RPO case, as the alternatives were generated, analyzes, monitoring and implementation of the information process itself evolved with the involvement of several areas according to the manager judgment. In this case, the planning decision-making process began to take shape throughout the implementation process itself as more information was being obtained by the manager.

In the MDE case we identified a different situation from the RPO case. Here there was no involvement of internal areas - the implementation of the decisions about the decision-making process occurred in isolation and were taken only by the manager; only at the end of the decision-making process, as initially planned, the manager involved his superiors.

In the NPD case, the usual process is to engage multiple areas and CEO throughout the process, i.e., it follows a pre-defined structure to discuss alternatives. Specifically, the generation of alternatives in the RPO case happened through the generation of ideas between the manager, superiors and other areas involved, while in the MDE case proposals were submitted by outside consultants interviewed for the manager's decision.

Thus, answering the question whether or not there was planning of the decision-making process, it can be stated that in cases RPO and MDE we observed the planning process for the development of decision-making, although in different time and with different efforts. In the NPD case, no planning effort was detected for the decision to launch the product because this process was already pre-defined. Though it was not possible in this study to investigate how and when this pre-defined process was developed, it is quite reasonable to assume that the process of deciding how to development and launch a product launch has been planned prior to the recognition of the problem or opportunity-making, given its recurrence in the company.

\section{Proposition 1}

The analysis of these cases led to the proposition of a graphical representation of a "planning effort" of a decision-making process. On the y-axis, the planning effort in decision making are represented. On the $\mathrm{x}$-axis the moment when the problem (or opportunity) requiring a decision is recognized, the period in which the planning process unfolds and when a decision is made are represented. On the y-axis it is represented the intensity of effort planning decision-making process developed over time as a decision-making process unfolds. 
Plotted in Figure 5, is a representation of hypothetical planning effort inspired by the three cases studied. Ep1 is the planning effort in the NPD case, Ep2 MDE case and Ep3 RPO case.

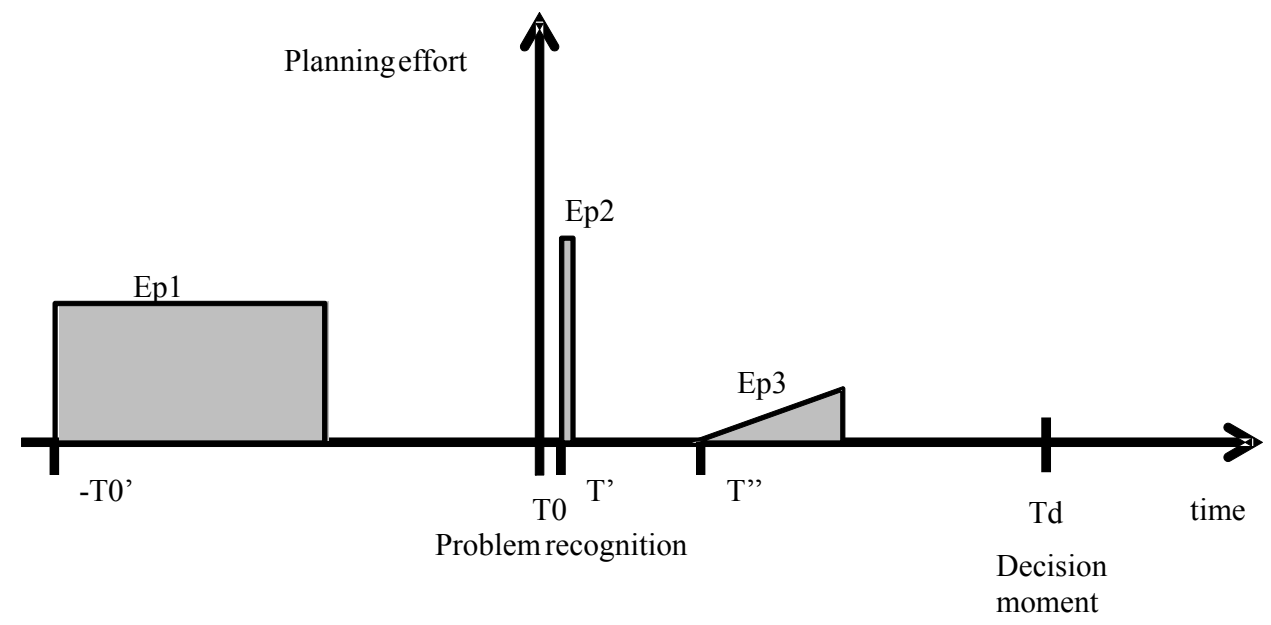

Figure 5. Representation of hypothetical planning effort in decision making

Source: Elaborated by the authors.

Ep1 is a kind of planning effort that happens before the decision-making process begins (moment- T0), in this case, even before the occurrence of the problem requiring a decision making process (moment T0). The time between moment- $\mathrm{T} 0$ and T0 can vary from days to years, depending on the complexity of the problem to be resolved. Thus the decision $\mathrm{Td}$ can be taken very distant in time from the planning period. The graphical representation suggested for this case proposes that this effort has been of average intensity and fairly continuous over a relatively long period. A similar case reported in the literature on previous planning decision making refers to the Toyota case. This organization uses forms to decide to launch their products (Torres \& Gati, 2008). These forms define a structure of predefined information that needs to be raised and summarized for developing cars that can be launched on the market.

Ep2 represents a second type of effort in planning that takes place immediately after the recognition of a problem (moment T'). The decision maker can quickly and intensely reflect — in a short period of time - about possible alternatives, the pros-and-cons of each possible solution and define a preferred one and what the next steps for achieving this solution. After the visualization of this solution the decision can be fastly taken or, as we observed in the MDE, some time may be spent to assess the feasibility of the solution and then the decision is taken (Td' moment). It is worth noting that this situation does not match the decision-making process investigated by (Klein, Calderwood, \& MacGregor, 1989) or reported by (Gladwell, 2005) in which decisions are made quickly and without reflection, but rather a situation in which a decision-maker quickly and consciously reflects and decides how to decide. On the other hand, a similar case was reported by (Sousa \& Yu, 2008) when a decision maker faced with the need to meet a customer in an emergency situation with a product still in the learning phase and out of the supplying range quickly and mentally established a plan to attempt to service this client.

Ep3 is a third type of planning effort, in which there is some delay to the start of planning ( $T$ " moment) in relation to the recognition of the problem (T0 moment). It's a situation where the decision maker need to exchange ideas with someone to start thinking about what to do, how and with whom to do. Besides, this process seems to be gradual and growing: as the manager obtains more information, steps that should be taken toward a preferred solution become clearer. Possibly, a significant portion of the strategic decisions that are structured based on the elements of a decision (Hammond, Keeney, \& Raiffa, 2002) use, or at least should use, a similar form of planning in the decision making process represented by Ep3.

What factors may be influencing the development of the planning in the decision-making process?

In the RPO and MDE cases, given the unprecedented nature of the problem, the addressing of the decision making was influenced by previous experiences and expertise of managers in their areas of expertise intuitively (Hodgkinson, Sadler-Smith, Burke, Claxton, \& Sparrow, 2009). Yet, in the NPD case, given the recurrence of the problem, the manager had a clear and structured procedure that should be followed to decide. Considering these 
cases, it was concluded that the nature of the problem-novel or recurrent-combined with the previous experiences influenced the development of the planning process. In the first two cases the achievement of planning was influenced by the use of previous experiences of makers under new problems; in the third case planning on deciding had already been developed by other makers prior to the occurrence of the problem of the studied the decision, given the recurrence of the problem.

In the MDE case, when asked about why the planning process, even if it is mentalized, the manager replied that a good plan reduces the risks of the decision and he believes the project risks have been reduced as a result of decision planning and the awareness of decision makers. In the MDE and RPO cases it was observed that the manager had the option of planning or not the decision making.

In the NPD case, the decision making was previously planned by the headquarters, i.e., there was no need for the planning of decision-making by the manager, since this is a planning process already established and formatted within the organization. From these cases it was also possible to conclude that "organizational culture in relation to the risks in decision making" may influence the planning decision-making process - when the organizational culture is targeted to reduce known risks, develops procedures on how a particular decision must be taken; when is not oriented, it is dependent on the characteristics of the decision maker in relation to risks.

Regarding the distribution of power, in the RPO case we observed that the low autonomy of the manager may have contributed to the non occurrence of the planning decision-making process, at least at first. In this case, the first step of the decision-maker after recognition of the problem was to contact his superior without even having an idea about what solution could be developed.

In the MDE case, despite the manager also had limitations in terms of autonomy to decide, this fact didn't limited the planning effort of the decision-making process - to the contrary, planning, one can say that it was relatively complex due to this limited autonomy.

In the DNP case, possible decision process problems that may arise due to low autonomy or power conflicts appear to be resolved, because the autonomy of who can decide about what in the decision process is also resolved by a pre-set decision-making process.

Regarding the alignment between personal interests of managers and the organization interests, in the three cases studied we observed the existence of such alignment.

In the RPO case, the interest in the manager side to seek a solution that would guarantee the survival of self-employment; in the side of the organization that the solution would be the survival of a unit that was profitable.

In the MDE case, interest on the manager's side would ensure continuity in the organization and find a solution that offered personal visibility, from the organizational perspective the interest would promote organizational change in a context of new managers; in the DNP case, as the procedure for deciding is already defined, an eventual misalignment between organizational and personal interests may not affect the planning of the decision-making process. Thus, it is suggested that when there is alignment between personal and organizational interests it is possible that the planning decision making process becomes easier, although it is not possible to confirm based on the cases we investigated that the existence of the alignment itself implies in the occurrence of planning decision-making - so we decided not to include this information as a factor that can facilitate the planning of decision-making.

The degree of knowledge about the problem, objectives and alternatives also proved an impact factor of the planning of the decision-making process. In the case of the three companies there was clarity about the problem to be solved and the objectives of the decision. In the RPO case, however, the alternatives were not clear to the manager at first - they were subsequently generated only when sharing with superiors and other areas. These findings suggest that the "degree of knowledge about the problem, objectives and alternatives" at the beginning of the decision-making process can influence the planning - favorably if greater, unfavorably if lesser.

The systemic view of the business by the manager appeared as a strong factor in planning the decision-making process. This impact was more evident at the moment, in the RPO case, was after the involvement of the superior and other areas to generate alternative; in the MDE case, this impact happened after consulting third parties to format a possible solution to the problem.

In synthesis, the following factors may influence the decision-making planning activity: 1. Organizational culture toward risk; 2 . Nature of the problem: new or recurrent; 3. Decision maker experience; 4 . Decision maker autonomy and systemic view and 5. Degree of knowledge of the problem, objectives and alternatives. Worth to notice that these factors were explicitally (e.g. Rajagopalan et al, 1993; Kunreuther \& Bowman, 1997) or 
implicitally (e.g. Keeney, 2004; Blenko et al, 2010, \& Klein et al, 1989) known as influencing the decision process; but the findings presented here, derived from empirically cases studied, seems to be the first ones where these factors could be associated to the decision-making planning process.

\section{Proposition 2}

Figure 6 summarizes a proposal representative of the factors that can influence the planning decision-making process.

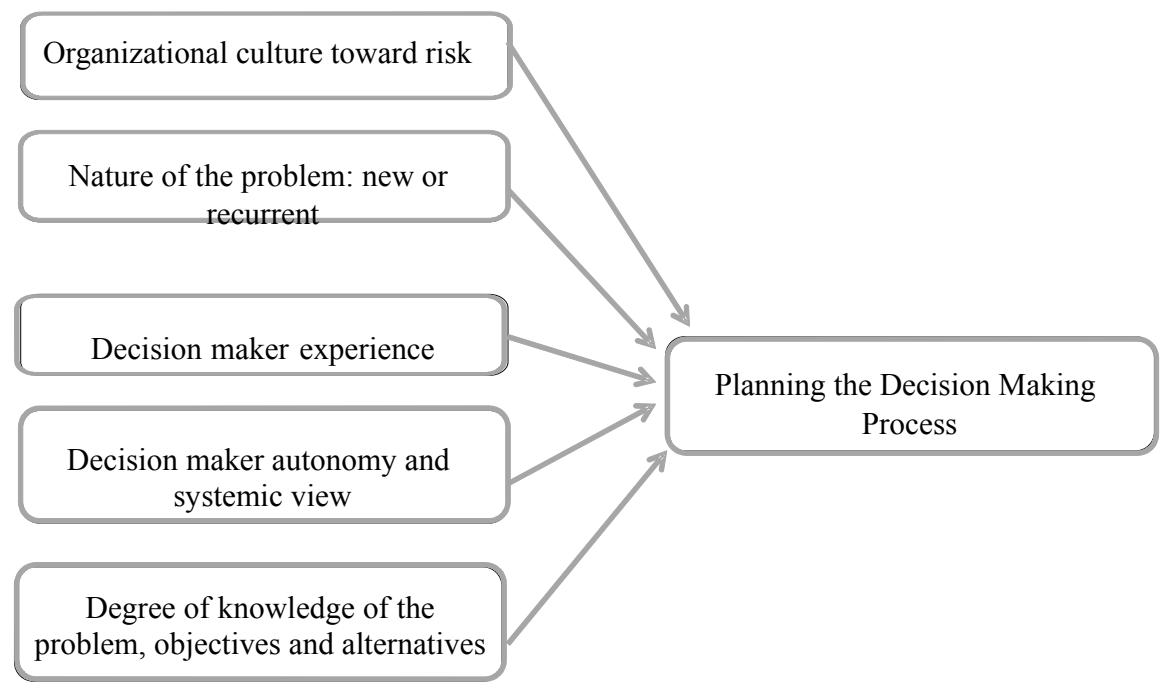

Figure 6. Factors that can influence the planning decision-making process

Source: Elaborated by the authors.

\section{Conclusions and Final Thoughts}

As highlighted in this study, it was found that a process of decision making can be planned. This planning may involve a greater control over the process to address new or recurrent problems, as well as focus the attention on the main elements of a decision - problem, objective, alternative and consequences. When a decision-making process is planned, actions to be developed along the decision-making process are defined and focused on what is or is not known to the decision maker in relation to these elements.

The three cases presented in this paper suggest that a decision-making planning effort may have a pattern. Its proposed here that a decision planning effort can occur at different degrees and at different temporal location in relation to when the problem occurred and the decision was taken. It can happen more intuitively and with less planning effort, if decision makers are experienced, or it may happen in the form of steps of pre-defined decision when the nature of the problem is recurrent. In such cases one can, for instance, plan forms with a set of information that needs to be surveyed and processed for the different stages of the process or even develop an information system, as noted in one of the cases investigated, to standardize decision-making and facilitate the decisions to be taken. Another result deserves to be highlighted: in spite of the decision making in all three cases being addressed at the strategic level of organizations, (Kladis \& Freitas, 1995), it was in the middle management of the organization (RPO and MDE cases; unable to get information about it in the DNP case) where the planning of the decision making took place. This result suggests that middle managers, when involved in strategic decision-making process, can have a greater influence and participation in the decision to be made by senior management than one might expect.

The results from this paper confirm that the meta-decision depends on the experience of the decision makers and the type of decision (recurrent or not), in other words, we suggest here that meta-decision may be path dependent (Nelson \& Winter, 1982).

The study of these three cases also provided a more dynamic way of looking at meta-decision making (Figure 5). In other words, these cases show that meta-decision making can evolve within a single decision process. This insight can open up another research agenda in meta-decision.

Among the factors that may be influencing the planning or not of the decision-making process (Figure 6), we add 
a few comments on two of them: organizational culture and systemic view.

The organizational culture regarding the risks in decision making can impact the prior planning of the decision-making process. (Dutra, 2002) reveals the importance of a learning culture in organizations as a way to respond to the turbulent environment which they operate. This learning culture spreads within the decision-making processes.

The systemic view of the business by the manager had a considerable impact on the planning of the decision-making process. (Senge, 2009) believes that organizations that develop of the tool of a systemic view in their employees, besides the development of learning disciplines related to collection and application of systemic vision can make a difference, creating innovation and a collective rethinking. It is registered, in this regard, recommendations for training and management development for organizations.

The cases investigated have brought some issues or situations that can be investigated in the future:

1) To what extent is the identification of a preferred solution by the manager not a necessary condition to justify starting the effort by decision maker regarding the planning of a decision-making process?

2) In cases of unsuccessful strategic decisions that have been planned what were the failures that occurred in the planning process and how they could be avoided?

Regarding the study limitations, it should be mentioned that the sample was selected by convenience, making it difficult to generalize the results found here. Besides, the risks and uncertainties were not considered in the decisions of specific cases. It is believed that this study has brought major contributions to the knowledge of the planning of decision-making in the field of descriptive decision theory and thus, practical information to improve the quality of decisions. The novelty that this study brings is that strategic decisions can be planned and the adoption of elements of a decision as a reference for this process can be a good guideline. Therefore, it is worth continuing to explore around this research topic with the development of new studies aimed at deepening of the variables investigated here, the research for new factors that might influence or not the planning decision-making process as well as how to seek the broadening of the scope of organizations researched.

\section{Acknowledgements}

This paper is a translated and revised version of an earlier paper presented at the XXXVI Encontro da ANPAD, 22-26 September 2012, Rio de Janeiro/RJ, Brazil.

\section{References}

Ansoff, I. (1988). The New Corporate Strategy (p. 288). Wiley.

Bazerman, M., \& Moore, D. (2010). Processo Decisório (p. 338). Elsevier.

Beach, L. R., \& Mitchell, T. R. (1978). A Contingency Model for the Selection of Decision Strategies. Academy of Management Review, 3(3), 439-449. http://dx.doi.org/10.2307/257535

Blenko, M. W., Mankins, M. C., \& Rogers, P. (2010). The Decision-Driven Organization. Harvard Business Review, 88(6), 54-62.

Clemen, R. T., \& Reilly, T. (2001). Making hard decisions with DecisionTools (2nd ed., p. 773). Pacific Grove: Duxbury Thomson Learning.

Flick, U. (2004). Uma introdução à pesquisa qualitativa (p. 188). Bookman.

Dutra, J. S. (2002). Gestão de pessoas: Modelo, Processos, Tendências e Perspectivas (p. 216). Atlas.

Gladwell, M. (2005). Blink: A decisão num piscar de olhos (p. 254). Rocco.

Hammond, J. S., Keeney, R. L., \& Raiffa, H. (2002). Smart Choices: A Practical Guide to Making Better Decisions (4th ed., p. 256). Rio de Janeiro: Crown Business.

Hodgkinson, G. P., Sadler-Smith, E., Burke, L. A., Claxton, G., \& Sparrow, P. R. (2009). Intuition in Organization: Implication for Strategic Management. Long Range Planning, 42(3), 277-297. http://dx.doi.org/10.1016/j.lrp.2009.05.003

Keeney, R. L. (2004). Making Better Decision Makers. Decision Analysis, 1(4), 193-204. http://dx.doi.org/10.1287/deca.1040.0009

Kickert, W. J. M., \& van Gigch, J. P. (1979). A metasystem approach to organizational decision-making. Management Science, 25(12), 1217-1231. http://dx.doi.org/10.1287/mnsc.25.12.1217 
Kladis, C. M., \& Freitas, H. M. R. (1995). O processo decisório: modelos e dificuldades. Revista Decidir, 2(8), 30-34.

Klein, G. A., Calderwood, R., \& MacGregor, D. (1989). Critical decision method for eliciting knowledge. IEEE Transactions on Systems, Man, and Cybernetics, 19(3), 462-472. http://dx.doi.org/10.1109/21.31053

Kunreuther, H., \& Bowman, E. H. (1997). A Dynamic Model of Organizational Decision Making: Chemco Revisited Six Years After Bhopal. Organization Science, 8(4), 404-413. http://dx.doi.org/10.1287/orsc.8.4.404

Langley, A. (1999). Strategies for Theorizing from Process Data. The Academy of Management Review, 24(4), 691-710. http://dx.doi.org/10.2307/259349

Malhotra, N. K. (2006). Pesquisa de Marketing: Uma Orientação (p. 720). Bookman.

March, J., \& Shapira, Z. (1987). Managerial Perspectives on Risk and Risk Taking. Management Science, 33(11), 1404-1418. http://dx.doi.org/10.1287/mnsc.33.11.1404

Miles, M. B., \& Huberman, A. M. (1994). Qualitative data analysis: An expanded sourcebook. Thousand Oaks: SAGE.

Mintzberg, H., Raisinghi, D., \& Theoret, A. (1976). The Structure of "Un-structured" Decision Processes. Administrative Science Quarterly, 21(June), 246-275. http://dx.doi.org/10.2307/2392045

Nelson, R., \& Winter, S. (1982). An evolutionary theory of economic change. Harvard University Press.

Nutt, P. C. (1991). A Taxonomy of Strategic Decisions and Tactics for Uncovering Alternatives. European Journal of Operational Research, 132(3), 505-527. http://dx.doi.org/10.1016/S0377-2217(00)00141-7

Nutt, P. C. (2002). Making strategic choices. Journal of Management Studies, 39(1), 67-96. http://dx.doi.org/10.1111/1467-6486.00283

Payne, J. W., Bettman, J. R., \& Johnson, E. J. (1993). The adaptive decision maker (p. 330). Cambridge University Press. http://dx.doi.org/10.1017/CBO9781139173933

Rajagopalan, N., Rasheed, A. M. A., \& Datta, D. K. (1993). Strategic decision processes: Critical review and future directions. Journal of Management, 19(2), 349-384. http://dx.doi.org/10.1177/014920639301900207

Robbins, S. P. (2000). Administração: Mudanças e Perspectivas (p. 524). Saraiva.

Roesch, S. M. A. (1999). Projetos de Estágio e de Pesquisa em Administração: Guia para Estágios, Trabalhos de Conclusão, Dissertações e Estudos de Caso (p. 336). Atlas.

Russo, J. E., \& Schoemaker, P. J. H. (1993). Tomada de Decisões: Armadilhas (p. 235). Saraiva.

Russo, J. E., \& Schoemaker, P. J. H. (2002). Winning decisions: getting it right the first time (1st ed., p. 329). I. Random House.

Senge, P. M. (2009). A Quinta Disciplina: Arte e Prática da Organização que Aprende (p. 532). Best Seller.

Shimizu, T. (2010). Decisão nas Organizações (3th ed., p. 448). Atlas.

Shrivastava, P., \& Grant, J. H. (1986). Empirically Derived Models of Strategic Decision-making Processes. Strategic Management Journal, 6(2), 97-113. http://dx.doi.org/10.1002/smj.4250060202

Simon, H. A. (1997). Administrative bahavior: A study of decision-making processes in administrative organizations (4th ed.). The Free Press.

Sousa, W. H. de, \& Yu, A. S. O. (2014). Decision Making Planning: The Meta-decision Approach. Engineering Management Research, 3(1), 41-55. http://dx.doi.org/10.5539/emr.v3n1p41

Sousa, W. H. de (2007). Decidindo como decidir: Desenvolvimento de uma estrutura conceitual. através de estudos de casos (Online). São Paulo: Faculdade de Economia, Administração e.

Contabilidade, Universidade de São Paulo. (2014, September 26). Management Doctorade thesis. Retrieved from http://www.teses.usp.br/teses/disponiveis/12/12139/tde-02042007-072002/

Sousa, W. H., \& Yu, A. S. O. (2008). Estruturas em decisões não estruturadas: Novas contribuições a partir do estudo das metadecisões. In XXXII Encontro da ANPAD (pp. 1-16). Rio de Janeiro: ANPAD.

Vroom, V. H. (2000). Leadership and the decision-making process. Organizational Dynamics, 28(4), 82-94. http://dx.doi.org/10.1016/S0090-2616(00)00003-6 
Wang, Z. (2000). Meta-Decision Making: Concepts and Paradigm. Systemic Practice and Action Research, 13(1), 111-115. http://dx.doi.org/10.1023/A:1009527707143

Yin, R. K. (2003). Case Study Research: Design and Methods (3rd ed.). Thousand Oaks, CA: Sage Publications, Inc.

\section{Appendix A}

\section{Interview protocol}

What was the decision in question? Do you consider the unprecedented in their professional practice?

When the problem has really become a problem for the organization?

What was taken into account before the decision making / what were the objects of reflection or prior review?

What was the time available to make the decision?

What was your degree of freedom for the decision making?

There was knowledge / expertise to solve the problem?

The problems involved were clear? / The objectives of the decision were declared?

People from other areas were involved in the decision process?

There was good relationship with these people? / Do they supported the process?

When people were really involved? / The people were involved early in the process (do they participated throughout the process?) or participated partially in the decision making process?

The problem was posed as a problem or as a technical challenge for the people involved?

What were the ethical considerations made during the process?

The decision was made to solve the problem once or there was a partial decision making in order to better address the problem in a second step?

\section{Copyrights}

Copyright for this articleis retained by the author(s), with first publication rights granted to the journal.

This is an open-access article distributed under the terms and conditions of the Creative Commons Attribution license (http://creativecommons.org/licenses/by/3.0/). 